\title{
Comparing active learning techniques: The effect of clickers and discussion groups on student perceptions and performance
}

\author{
Ryan J. Walker, Brooke R. Spangler, E. Paige Lloyd, Bethany L. Walker, Peter M. Wessels, Amy \\ Summerville \\ Miami University, Oxford, Ohio
}

\begin{abstract}
Instructors often implement technology-based active learning pedagogies, such as clickers, to maximise student engagement and facilitate learning outcomes. Despite the abundance of clicker research, no work has directly compared student performance as well as student perceptions of clickers to a distinct, non-technological active learning pedagogy. Using a mixed methods quasi-experimental design, the current research compared clickers to a collaborative active learning pedagogy, student discussion groups. As predicted, clickers were evaluated more favourably than discussion groups. Qualitative analysis of students' openended evaluations augmented these quantitative findings. Secondary analyses suggested that student performance was equivalent for clicker and discussion sections. Together, these results suggest that incorporating clickers into introduction courses may improve students' attitudes towards the instructor's pedagogy without any negative consequences for performance.
\end{abstract}

\section{Introduction}

Clickers, personal response devices in which students respond to a question presented during a lecture, are an increasingly common application of technology in the classroom. Clickers are often used to increase student engagement, a core goal of instructors (Buskist \& Benassi, 2012; Hake, 1998). Despite the growth of clicker research, no work has directly compared clickers to other pedagogical techniques aside from hand-raising and similar response-based systems (Anthis, 2011; Brady, Seli, \& Rosenthal, 2013; Morgan, 2008). Thus, in the current research we explored how two active learning pedagogies that differ in their integration of technology - clickers versus discussion groups - influenced student perceptions and performance.

\section{The efficacy of clickers}

Instructors of university courses often strive to push students beyond simple memorisation of material. Active learning strategies, or strategies that facilitate participation and encourage students to engage with the material in deeper ways, are often implemented to fulfill these goals (Buskist \& Benassi, 2012; Hake, 1998; Handelsman et al., 2004; Pratton \& Hales, 1986). One such active learning strategy is incorporating audience response systems such as clickers. Students use clickers to respond to the instructor's questions and are able to view an anonymous summary of the class's responses in real time. Instructors can later view individual student responses to assess an individual student's performance or attendance (Chien, Chang, \& Chang, 2016; Lantz, 2010).

Since the advent of clickers and other audience response systems, instructors and researchers have examined how this technology influences student engagement and subsequent performance (Hunsu, Adesope, \& Bayly, 2016; Trees \& Jackson, 2007). One clear benefit of the clicker system is that it provides all students with an opportunity to respond anonymously to a question posed by the instructor without fear of being singled out for an incorrect response (Benson, Szucs, \& Taylor, 2016; Kay \& LeSage, 2009; Lantz, 2010). It is therefore not surprising that when clickers are used in the classroom, students find the class more engaging, interesting and entertaining (Barnett, 2006; Benson et al., 2016; Blasco-Arcas, Buil, Hernández-Ortega, \& Sese, 2013; Chien et al., 2016; Stevens \& Fontenot, 2017). Numerous studies have also shown that clickers are effective, such that student performance on exams increases compared to traditional classrooms without clickers or nontechnology-based response systems (e.g., holding up response cards; Blasco-Arcas et al., 2013; Brady et al., 2013; Hunsu et al., 2016; Shaffer \& Collura, 2009). In addition, compared to control or hand-raising groups, the anonymity of clickers creates a more comfortable classroom environment that facilitates student 
participation and decreases student conformity to questions in class (i.e., increases variability of responses to questions; Freeman, Blayney, \& Ginns, 2006; Stowell \& Nelson, 2007; Stowell, Oldham, \& Bennett, 2010). Despite these advantages, clickers are accompanied by some drawbacks. Technical issues are common, and clickers are expensive, which are major complaints from students (Barnett, 2006; Benson et al., 2016; Poirier \& Feldman, 2007).

The positive implications of clickers may not be unique to this pedagogy, however. Clickers, like other learning activities, incorporate techniques subsumed by other, non-technological active learning pedagogies, such as asking students to respond to a specific question posed by a facilitator (Anthis, 2011; Kornell, Rabelo, \& Klein, 2012). When controlling for these similarities, studies have found that there are no differences between clickers and traditional classrooms on exam performance or differences on exam performance are relatively small (see Anthis, 2011; see also Martyn, 2007; Morgan, 2008; Symister, VanOra, Griffin, \& Troy, 2014). Thus, there have been mixed reviews about the overall benefit of clickers (Kay \& LeSage, 2009). While some researchers argue there are performance benefits, others argue if benefits exist they are small and potentially outweighed by technical and financial drawbacks. We suggest that research examining student perceptions of clickers in combination with student performance could be informative in decisions for or against clicker use in the classroom.

Furthermore, there are numerous techniques an instructor can bring into the classroom that produce favourable student outcomes (e.g., Lloyd, Walker, Metz, \& Diekman, in press). Given arguments that research on a specific educational technique should compare that method to standard or established practices (Whitehurst, 2010), it is problematic that many studies examining clickers have compared this classroom engagement technique to control methods (e.g., Morling, McAuliffe, Cohen, \& DiLorenzo, 2008). This research demonstrates that clickers have a more favourable impact on student perception and learning outcomes compared to non-active learning control methods. However, the lack of research comparing clickers to other effective active learning pedagogies makes it difficult to make a valid comparison to established active learning classroom techniques, rather than outdated control techniques. In the current work, we compared clickers to the established classroom engagement technique of discussion groups to better understand the benefits and drawbacks that clicker technology offers.

\section{Discussion groups: A point of comparison}

One well-established non-technological active learning pedagogy that provides a useful comparison point for clickers is collaborative learning (i.e., students interact and work together towards a small goal; Barkley, Cross, \& Major, 2014; Handelsman et al., 2004; Kirschner, Paas, \& Kirschner, 2009; Yoder \& Hochevar, 2005). Discussion groups, which provide students with the opportunity to interact and discuss material in small breakout groups (as opposed to the class as a whole) are one such collaborative learning technique that instructors can implement in the classroom. Compared to individual work, implementing student discussions in the classroom has been shown to improve academic achievement and student attitudes towards the class (Johnson, Johnson, \& Smith, 1998; Kirschner et al., 2009; Springer, Stanne, \& Donovan, 1999). Numerous other studies have demonstrated that student discussions encourage students to explore specific topics, process material more deeply and create meaning of the material (Kirschner et al., 2009; Prince, 2004). Moreover, providing students with the opportunity to discuss course topics with peers encourages participation and critical thinking and generally facilitates learning (Garrison, Anderson, \& Archer, 2001; Lantz, 2010; Smith et al., 2009). Finally, discussion groups are cost-effective because they typically do not require students to purchase additional materials.

However, as with most pedagogies, there are potential drawbacks with implementing student discussions. First, students in introductory-level courses often have limited knowledge of the topic, which may make group discussions particularly difficult (Lantz, 2010), and students may therefore perceive this pedagogy to be relatively demanding or time-consuming. Additionally, group discussions may not be beneficial for all students in the classroom when compared to techniques in which individuals work on their own (Stenlund, Jönsson, \& Jonsson, 2016). For instance, some students inevitably dominate group discussions (Lantz, 2010), which may have a negative impact on other students. These drawbacks can be contrasted with clickers, which 
have been shown to create a comfortable environment that provides an opportunity for all students to participate anonymously (Barnett, 2006; Benson et al., 2016; Freeman et al., 2006; Stowell et al., 2010). The differences between these active learning pedagogies suggest that, relative to discussion groups, clickers may be evaluated more positively by students and may lead to differences in performance.

\section{The current research}

In order to examine student perceptions of clickers and discussion groups as well as performance outcomes, we implemented these pedagogies in different sections of Introduction to Psychology. Two sections (i.e., two separate classes of students) used clickers and one section used student discussion groups. We opted to focus primarily on how student perceptions are influenced by pedagogy type because there are inherent methodological concerns when making comparisons in exam scores between distinct pedagogies (e.g., length of time spent on a specific question varies; one pedagogy covers more material in a given session). This can make it difficult to elucidate the factors that are producing differences in exam scores. Nevertheless, we include our assessment of student exam performance and grade point average (GPA) as a secondary purpose of the study. We hypothesised that pedagogy type would predict student perceptions, such that introductorylevel students would hold more favourable attitudes of clickers than of discussion groups. Additionally, due to the more demanding nature of discussion groups, we hypothesised that the clicker pedagogy would be evaluated by students as adding less work to the course than discussion groups. We had no a priori hypotheses for student performance given the somewhat equivocal findings in the clicker literature.

\section{Method}

The current research used a mixed methods design. We conducted a quasi-experimental comparison of the two techniques via quantitative measures, including questionnaire measures of student perceptions and actual course performance, as well as via a qualitative analysis of student responses to open-ended questions about their experience with and perceptions of both technologies.

\section{Participants}

Two hundred and twenty-one students (age $M=18.68, S D=1.17 ; 56.56 \%$ female; $76.02 \%$ freshman) enrolled in three sections of Introduction to Psychology at a medium-sized university in the Midwestern United States volunteered to participate in the quasi-experimental study. Introduction to Psychology is one of the more popular options for the university's social science general education requirement and is specifically required for students in the premedical studies program as well as several social science majors, including psychology. Students typically (but not exclusively) take the course as first- or second-year students. Although demographic information was not collected for study participants (aside from what is reported above), the course is generally representative of the university's demographics. Of students enrolled at this campus of the university in Fall 2016 (the year after this study was conducted), 0.2\% identified as Native American, 2.1\% as Asian American, 3.1\% as African American, fewer than $0.1 \%$ as Pacific Islander, $4 \%$ as Hispanic or Latino, and 3.3\% as multiracial. Of the students, $13.4 \%$ were non-US residents, primarily from China.

Participants attended each course four days per week for 55 minutes. This research was conducted during the Fall 2015 semester under the approval of Miami University's Institutional Review Board. The rights of participants were protected, and applicable human research guidelines were followed.

\section{Materials}

\section{Courses}

All three sections covered similar material throughout the semester. Advanced graduate students (one male, one female) taught two sections of the course ( $n s=41,56$; clickers), and one professor (male) taught the third 
section ( $n=124$; discussion groups). Sections of the course operated independently, and each section covered generally similar but non-identical material throughout the semester.

\section{Clicker pedagogy}

The two graduate student instructors implemented the TurningPoint student response system in their sections. Each day, students were asked to answer to approximately four clicker questions, although this varied slightly between lectures. Students were presented with a question on the projector and they were given approximately 45 seconds to respond with their personal clicker devices (the personal mobile device version of clickers was not used in these courses). Students were asked not to discuss the question or answer with fellow students. After all students responded to the question, the instructor presented a graph depicting the distribution of responses, and students were verbally given the correct answer. The instructors typically provided the rationale as to why one answer was correct and why other answers were incorrect. The instructor of section one $(n=41)$ used clickers during each lecture to reiterate important concepts. The instructor of section two $(n=56)$ used clickers to review the previous lecture's material. We manipulated this to ensure that student perceptions and performance did not differ based on how the clickers were implemented. Both instructors occasionally used clickers to demonstrate psychological phenomena before teaching students about those phenomena.

\section{Discussion section pedagogy}

The remaining instructor implemented structured student-led discussion groups. For this section of the course, the university's online registration system created 11 subsections that served as discussion groups for the larger course. Thus, each discussion group included 9-12 (of the total 124) students. The entire class had three common lecture sessions each week, and each discussion group met separately for one session each week. The discussion group meetings were evenly spread throughout the semester. By the end of the semester, each discussion group had met 14 times, which equated to roughly one discussion group meeting for every three regular lecture periods.

The instructor recruited and trained undergraduate discussion leaders (roughly 50\% sophomores, 50\% juniors and seniors); some discussion leaders were enrolled in this instructor's previous courses, and other faculty members recommended other discussion leaders. Each discussion group was assigned two leaders. The instructor attempted to match the level of skill and experience of the leaders across groups. Additionally, when possible, the instructor sought to pair male and female discussion leaders together.

The instructor selected the topics and provided the material that would be covered by the discussion leaders each week, although the discussion leaders had some freedom to revise activities as they saw fit. Topics typically focused on critical thinking with an emphasis on research methods (e.g., correlation and causation, descriptive research methods). Discussion groups also provided an opportunity for students to get help with class assignments and learn how to use course-related resources (e.g., the PsycINFO database system).

\section{Student perceptions}

Similar to past studies of student perceptions of pedagogy (Barnett, 2006; Blasco-Arcas et al., 2013; Trees \& Jackson, 2007), 11 standardised survey questions and 3 open-ended questions assessed students' perceptions of the technique to which they were exposed. In developing the questionnaire, we examined past work and selected major themes that are often cited when describing the benefits of active learning pedagogies (e.g., interactive, better learning; Barnett, 2006). In the 11 standardised survey questions, students were asked if clickers [discussion groups] were effective at getting them to think about material; were engaging; helped them get a better grade; helped them retain material; were interactive; improved their performance; helped prepare them for exams; made the class more interesting; made the class more entertaining; made them feel more comfortable to participate in class; added more work to the course. Responses were made on a scale from 1 (not at all) to 7 (definitely). In the 3 open-ended questions, students were asked to name one thing they enjoyed about the clickers [discussion groups], to name one thing they did not enjoy about the clickers [discussion groups], and to suggest one change the instructor could make to improve the clicker [discussion section] experience. In addition to these questions, students rated their instructor on competence and 
approachability/warmth to control for differences between the instructors. Responses for these questions were made on a scale from 1 (not at all) to 7 (definitely).

\section{Student performance}

Each section had three exams throughout the semester, not including the final exam. Each exam was comprised of 40 to 50 multiple-choice questions worth a total of 80 to 100 points. Each student's lowest exam score for the semester was dropped in each course (i.e., it was not included in his/her final grade). The order of content in the clicker versus discussion groups differed slightly, so the three exams corresponded to different topic areas for the different pedagogies. We therefore averaged the three exams into a single exam performance score. The Institutional Review Board granted approval for comparing averaged exam scores from each section. However, approval was not granted for linking individual student exam scores to the student perception data. In addition to assessing exams scores, we also assessed overall course GPA, reported on a 4.0 scale.

\section{Procedure}

The instructors of each course implemented the assigned pedagogy at the beginning of the semester. Approximately 4 weeks before the end of the semester, each instructor asked his or her section to complete the student perceptions rating sheet in class. Students were asked to be honest in their feedback, as their responses on the rating sheet would help improve future students' experiences in the course. Some students were not present in class the day the student perception rating sheet was administered and therefore did not provide responses. A total of 91 students (38 and 53) in the clicker sections and 91 students in the discussion section provided responses. We excluded one additional participant from the discussion section because the student's perception rating sheet was incomplete, which resulted in a final sample size of 181 participants.

\section{Results}

\section{Quantitative analyses}

\section{Preliminary analyses}

Before conducting the primary analyses on the student perceptions, we wanted to ensure we appropriately controlled for instructor differences, primarily because gender and teaching experience differed between instructors and between pedagogies. Thus, we conducted a one-way ANOVA on student perceptions of instructor competence and on instructor approachability/warmth between the three sections. There were no significant differences in student perceptions of instructor competence between the three sections, $F(2,178)=$ 2.71, $p=.07, \eta_{\mathrm{p}}{ }^{2}=.03$. However, there were differences in student perceptions of instructor approachability/warmth, $F(2,178)=10.31, p<.001, \eta_{\mathrm{p}}{ }^{2}=.10$ (partial eta squared $\left[\eta_{\mathrm{p}}{ }^{2}\right]=.10$ corresponds to a medium effect). A Bonferroni post-hoc comparison revealed that students in the clicker section with the female instructor perceived their instructor to be significantly more approachable and warm $(M=6.85, S D=$ $.41)$ than the male instructor in the discussion section $(M=6.21, S D=.99, p<.001)$. There was a nonsignificant difference in approachability/warmth between the male instructor in the clicker section $(M=6.45$, $S D=.76)$ and the female instructor in the clicker section $(M=6.85, S D=.41, p=.06)$, as well as the male instructor in the clicker section and the male instructor in the discussion section $(M=6.21, S D=.99, p=.40)$. We controlled for instructor ratings of competence and approachability/warmth in the main analyses on student perceptions; however, the direction and significance of the focal results were unchanged when covariates were not included.

Next, we tested for differences in student perceptions between the two sections that implemented clickers. A series of independent samples $t$-tests were conducted and revealed that there were no significant differences in student perceptions between the two sections, $t \mathrm{~s}<1.22$, $p \mathrm{~s}>.23$, $d \mathrm{~s}<.25$ (Cohen's $d<.25$ corresponds to a small effect). Thus, we collapsed across clicker sections in the subsequent student perception analyses. 
Before conducting the main analysis on the relation between pedagogy type and student perceptions, we tested if it was possible to reduce student perceptions into fewer factors in order to decrease the likelihood of obtaining a Type I error. We performed a principal components analysis with an orthogonal varimax rotation. When we entered the 11 perceptions into the analysis, results revealed two eigenvalues greater than 1.0, which accounted for $71.50 \%$ of the variability (see Table I). The first factor, overall effectiveness and student engagement, was comprised of ten student perceptions (think about material; engaged; improved grade in course; retain material in the long term; interactive; performance improved; helped prepare for exams; made class more interesting; made class more entertaining; more comfortable participating). We defined overall effectiveness and student engagement as perceiving that the pedagogy facilitated learning and was beneficial for engagement and participation $(\alpha=.95)$. The second factor, added more work, was comprised of the perception that the pedagogy added more work to the course, which was unrelated to the perception of effectiveness and engagement, $r=.00, p=1$. We used standardised factor scores in subsequent analyses.

\section{Student perceptions}

Our central question was the relationship between pedagogy type and student perceptions. We anticipated that clickers would be perceived as more effective and engaging than discussion groups, and also as requiring less work. In order to compare the pedagogies while also controlling for the continuous factors of instructor warmth and competence as covariates, we regressed overall effectiveness and student engagement onto the two covariates of instructor competence and instructor approachability/warmth as well as the dichotomous pedagogy variable $(0=$ discussion groups, $1=$ clicker sections). Pedagogy type was significantly related to overall effectiveness and student engagement, $\beta=.41, t(175)=6.09, p<.001$, as were both covariates, $\beta \mathrm{s}>$ $.19, t \mathrm{~s}>2.58, p \mathrm{~s}<.02$. Thus, as predicted, clickers were rated as more effective and engaging than were discussion groups, even when controlling for instructor competence and approachability/warmth.

We conducted the same linear regression analysis on student perceptions that the pedagogy added more work. This analysis revealed that, as expected, clickers were marginally associated with lower student perceptions that the pedagogy added more work, $\beta=-.15, t(175)=-1.82, p=.07$. Both covariates were unrelated to added more work in this model, $\beta \mathrm{s}<.07, t \mathrm{~s}<.81, \mathrm{ps}>.42$. Thus, in partial support of our prediction, clickers were evaluated as adding marginally less work to the course than discussion groups when controlling for instructor competence and warmth.

Table 1

Factor loadings for principal components analysis of student perceptions

\begin{tabular}{|c|c|c|}
\hline & \multicolumn{2}{|l|}{ Component } \\
\hline & Overall effectiveness and student engagement & Added more work \\
\hline Think about material & .839 & .023 \\
\hline Engaged & .854 & -.089 \\
\hline Improved grade in course & .837 & .072 \\
\hline Retain material in the long term & .848 & .240 \\
\hline Interactive & .710 & -.054 \\
\hline Performance improved & .877 & .103 \\
\hline Helped prepare for exams & .869 & .069 \\
\hline Made class more interesting & .834 & -.146 \\
\hline Made class more entertaining & .787 & -.223 \\
\hline More comfortable participating & .769 & -.114 \\
\hline Added a lot of work to course & .069 & .948 \\
\hline
\end{tabular}

Note. Factor loadings $>.50$ are in boldface.

\section{Student performance}

Our secondary question was the relationship between pedagogy type and student performance. We first tested for differences in student exam scores between the two sections that implemented clickers. An independent samples $t$-test revealed that the average exam performance did not differ for the two clicker sections, $t(95)=$ $.80, p=.43, d=.16$. Thus, we collapsed the exams across clicker sections. We then conducted an independent 
samples $t$-test comparing the average exam score for the clicker sections to the discussion section. This analysis revealed that exam performance did not differ between the pedagogies, $t(215)=.96, p=.34, d=.14$.

Lastly, to supplement these exam analyses, we assessed overall course performance by examining the average course GPA for each section. The average GPA in the clicker sections was 3.70 and 3.51, whereas the average GPA in the discussion section was 3.20. Overall, students in the clicker sections performed equivalently on exams and slightly better in the course overall relative to students with the discussion pedagogy.

\section{Qualitative analyses}

Thematic analysis was used to interpret data from the three open-ended student perception questions (Braun \& Clarke, 2006). Two independent coders, one of whom was blind to hypotheses, read over the responses twice. Each coder independently generated an initial list of themes observed in the data. Next, the coders shared these lists of themes with each other and decided on a final list of themes. The coders then independently assigned themes to each open-ended response. Although it was possible for a response to be assigned more than one theme, this was extremely rare, occurring in fewer than $2 \%$ of cases. When responses reflected more than one theme, both themes were included in analyses. Responses that did not relate to the pedagogy method (e.g., feedback about the professor or class as a whole) were coded as other. The inter-rater reliability was high for all three open-ended questions (question $1, \kappa=.82, p<.001$; question $2, \kappa=.89, p<$ .001 ; question $3, \kappa=.88, p<.001)$. The two coders resolved the few disagreements through discussion.

Due to the inherent qualitative differences between clickers and discussion groups, student responses were almost entirely qualitatively different between these two methods. In other words, the majority of responses about clickers were specific to this method and were irrelevant for discussion groups (e.g., technical problems) and vice versa. However, students occasionally had similar responses across pedagogy methods or had responses about one method that theoretically could have been made about the other method (e.g., does not help learning). Thus, percentages of students whose responses reflect each theme are provided for both pedagogies in Tables 2, 3 and 4 regardless of whether the theme was completely irrelevant for one pedagogy.

For the prompt 'Name one thing you enjoyed about clickers/discussions' (see Table 2), five themes were found in the data for clickers. The most common response was that clickers help students learn. For example, students wrote, 'helps me understand material better', and 'I love being able to test my knowledge to learn what I need to study'. In addition, as expected based on previous research (Shaffer \& Collura, 2009; Stowell et al., 2010), students liked the interactive and anonymous nature of clicker questions. Finally, students enjoyed funny clicker questions and learning how other students responded to clicker questions. Seven themes were observed for discussion groups. The most frequent response was that students enjoyed the environment created by the discussion groups, which they described as a comfortable, laid-back small-group setting. Examples of this theme include 'I liked being in a smaller class setting' and 'they're relaxing/laid back'. Students also indicated that they liked their discussion leaders and the interactive and enjoyable atmosphere of the discussion groups. Finally, students enjoyed the fact that discussion groups helped them learn class material, helped them complete class assignments and provided opportunities to interact socially with other students. 
Table 2

Frequency of responses: 'Name one thing you enjoyed about clickers/discussions'

\begin{tabular}{lcccc}
\hline & \multicolumn{2}{c}{ Clickers } & \multicolumn{2}{c}{ Discussion groups } \\
Theme & $\mathbf{\%}$ & $\boldsymbol{n}$ & $\mathbf{\%}$ & $\boldsymbol{n}$ \\
\hline Helps learning & 35.2 & 32 & 10.0 & 9 \\
Funny/enjoyable & 14.3 & 13 & 6.7 & 6 \\
Knowing how others in the class responded & 14.3 & 13 & 0 & 0 \\
Interactive & 11.0 & 10 & 16.7 & 15 \\
Answering anonymously & 8.8 & 8 & 0 & 0 \\
Comfortable environment & 0 & 0 & 23.3 & 21 \\
Discussion section leaders & 0 & 0 & 15.6 & 14 \\
Helps with class assignments & 0 & 0 & 11.1 & 10 \\
Social opportunity & 0 & 0 & 3.3 & 3 \\
Didn't enjoy anything & 2.2 & 2 & 6.7 & 6 \\
Other & 14.3 & 13 & 6.7 & 6 \\
\hline
\end{tabular}

For the prompt 'Name one thing you did not enjoy about clickers/discussions' (see Table 3), seven themes were identified in the data for clickers. Similar to previous research (Barnett, 2006; Benson et al., 2016), students most frequently indicated that they did not enjoy the technical problems that arose with the clickers. One student wrote, 'sometimes clickers don't work, it's annoying to stop class'. Although the most frequent complaint was technical issues, other students wrote that the questions moved too quickly, that there were not enough clicker questions and that the questions were too easy. Other dislikes included that the clickers were expensive and were used to monitor attendance. Notably, nearly half of the students (48.4\%) indicated that there was nothing they disliked about the clickers.

In the discussion section data, seven themes were observed. The most frequent response indicated that students felt discussion groups wasted time or were pointless. For example, students wrote, 'sometimes I feel like they do not accomplish enough and that they are a waste of my time' and 'lot of wasted time, sometimes feels unnecessary'. Other dislikes included that discussion groups did not help learning, were held at an inconvenient time and were boring. Some students indicated problems with the discussion section leaders (e.g., 'leaders did not work well together') or that the material that was presented in discussion groups could be presented in an easier way. Finally, students wrote that discussion groups were unhelpful in some way (e.g., 'they sometimes felt un-relatable to what we were learning in lecture').

For the prompt 'Suggest a change the instructor could make to improve the clicker/discussion experience' (see Table 4), four themes were found in the data for clickers. The majority of students indicated that they would like more clicker questions. Other students wrote that they would like the clicker questions to be harder, to be more reflective of exam questions or to review previously covered material. Three themes were observed in the discussion section data, the most common being that students would like the discussion groups to be made more helpful in some way. For example, students wrote, 'focus more on content from class' and 'make the material more relevant and connected to the class lecture material'. Students also suggested that problems with discussion leaders be addressed and that the frequency or duration of the meeting time be changed. 
Table 3

Frequency of responses: 'Name one thing you did not enjoy about clickers/discussions'

\begin{tabular}{|c|c|c|c|c|}
\hline \multirow[b]{2}{*}{ Theme } & \multicolumn{2}{|c|}{ Clickers } & \multicolumn{2}{|c|}{ Discussion groups } \\
\hline & $\%$ & $n$ & $\%$ & $n$ \\
\hline Technical problems & 18.7 & 17 & 0 & 0 \\
\hline Wastes time/pointless & 6.6 & 6 & 26.7 & 24 \\
\hline Questions move too quickly & 5.5 & 5 & 0 & 0 \\
\hline Expensive & 5.5 & 5 & 0 & 0 \\
\hline Clickers being used to monitor attendance & 4.4 & 4 & 0 & 0 \\
\hline Questions are too easy & 3.3 & 3 & 0 & 0 \\
\hline Not enough clicker questions & 3.3 & 3 & 0 & 0 \\
\hline Does not help learning & 0 & 0 & 10.0 & 9 \\
\hline Discussion groups held at inconvenient time & 0 & 0 & 6.7 & 6 \\
\hline Discussion groups are unhelpful in some way & 0 & 0 & 5.6 & 5 \\
\hline Boring & 0 & 0 & 5.6 & 5 \\
\hline Problems with discussion leaders & 0 & 0 & 4.4 & 4 \\
\hline Material could be learned via easier method & 0 & 0 & 3.3 & 3 \\
\hline Nothing was unenjoyable & 48.4 & 44 & 28.9 & 26 \\
\hline Other & 4.4 & 4 & 7.8 & 7 \\
\hline
\end{tabular}

Table 4

Frequency of responses: 'Suggest one change the instructor could make to improve clicker/discussion experience,

\begin{tabular}{lcccc}
\hline & \multicolumn{2}{c}{ Clickers } & \multicolumn{2}{c}{ Discussion groups } \\
Theme & \% & $\boldsymbol{n}$ & \% & $\boldsymbol{n}$ \\
\hline Incorporate more clicker questions & 24.2 & 22 & 0 & 0 \\
Make questions more difficult & 13.2 & 12 & 0 & 0 \\
Make questions reflective of exam questions & 4.4 & 4 & 0 & 0 \\
Make review questions & 4.4 & 4 & 0 & 0 \\
Make discussion groups more helpful & 0 & 0 & 31.1 & 28 \\
Address problems with discussion leaders & 0 & 0 & 8.9 & 8 \\
Change frequency/duration of meeting time & 0 & 0 & 7.8 & 7 \\
Don't make any changes & 37.4 & 34 & 32.2 & 29 \\
Other & 16.5 & 15 & 20.0 & 18 \\
\hline
\end{tabular}

In sum, although the quantitative results revealed that students evaluated clickers more positively than discussion groups, these qualitative findings provided some insight as to why students evaluated clickers more favourably. When asked to describe what they liked about clickers and discussion groups, students provided several positive evaluations of each of these pedagogies. In contrast, when asked what they did not enjoy and what they would change about these pedagogies, students provided more negative evaluations of discussion groups compared to clickers. Specifically, students indicated that they wanted the discussion groups to generally be more helpful (e.g., 'Make the material more relevant') and that discussion groups sometimes wasted time and did not help learning (e.g., 'Not effective, waste of time'). The most common complaint against clickers was about technical problems, and when students were asked to suggest a change, most students indicated that they would incorporate more clicker questions or would not change anything at all (e.g., 'More questions throughout lecture').

\section{Discussion}

With the burgeoning use of clickers in higher education, it is increasingly important for instructors to understand the efficacy of this technology. We sought to extend previous findings by evaluating if student perceptions were more favourable towards clickers than a non-technological active learning pedagogy or structured student discussion groups, as well as if performance differed between these pedagogies. Both the 
clicker and student discussion pedagogies incorporate similar techniques (e.g., students respond to questions posed by a facilitator) in an attempt to increase student engagement and participation. Nevertheless, in line with our predictions, clickers were more positively evaluated than discussion groups. Moreover, students performed equivalently on exams, although overall course GPA was descriptively higher in the clicker sections. Therefore, in addition to replicating previous findings about the benefits of using clickers (e.g., increased engagement, helps learning; Barnett, 2006; Patry, 2009), these results suggest that clickers have a positive effect on student evaluations without negative consequences for performance. This contribution is noteworthy because a majority of clicker literature has examined the clicker pedagogy on its own or has compared clickers to traditional classrooms (Blasco-Arcas et al., 2013; Shaffer \& Collura, 2009). In other words, much of the previous work has shown that an active learning pedagogy is more beneficial than a classroom without an active learning pedagogy (e.g., Shaffer \& Collura, 2009). This research indicates that future work should continue to compare clickers to other established pedagogies in order to help instructors understand which pedagogies will facilitate attainment of their goals in the classroom.

Importantly, the findings from the current study lead to a number of practical recommendations for instructors. First, by revealing that students view clickers more positively than structured discussion groups, this work indicates that instructors should consider employing the clicker pedagogy if they are interested in boosting student engagement and interest during class time. Even though there were no performance differences in the current study, using teaching strategies that are viewed favourably can help instructors build rapport (Buskist \& Benassi, 2012), and student attitudes about a pedagogy may even be reflected in student motivation and performance (Armbruster, Patel, Johnson, \& Weiss, 2009; cf. Wesp \& Miele, 2008). In addition, clickers took up substantially less class time than structured discussion groups. When instructors are selecting a technique for their classroom, they are naturally bound by time. The current work suggests that instructors seeking to save time on in-class activities can select the clicker pedagogy (over the more timeintensive structured discussion group pedagogy) without causing any harmful effects on student attitudes or learning. Finally, the current study suggests that instructors may be able to incorporate clickers in their classroom to a greater extent. Oftentimes, clickers are used to quickly review material or so that students can answer sporadic questions during class (Lantz, 2010). Both the quantitative and qualitative data in the current study indicate that students genuinely enjoyed clickers and they would have liked to use them even more in class. This enthusiasm towards clickers suggests that instructors may be able to heavily incorporate this technology in their classroom in new ways that could benefit student learning (e.g., Lloyd et al., in press).

It is important to note, however, that clickers and structured discussion groups are two unique pedagogies with distinct advantages and drawbacks. For example, benefits unique to clickers include equal opportunity for each student to participate and the opportunity to view the responses of classmates. However, clickers also involve financial cost and the potential for technical problems. On the other hand, benefits unique to discussion groups include the opportunity for students to receive help from discussion leaders on class assignments, to interact with other students socially and to process material in a more in-depth manner. Problems with discussion section leaders and additional work for students and instructors are potential drawbacks (Lantz, 2010). These qualitative differences between the two pedagogies may be some of the reasons why student perceptions of these techniques differed. Additionally, the qualitative differences also indicate that instructors should weigh the benefits and drawbacks and decide on the pedagogy that best fits their classroom needs and teaching style.

\section{Limitations and future directions}

Despite the large differences in student perceptions between the pedagogies, this study is not without limitations. For instance, in the current study, we lacked random sampling, the sections differed in size, and the sections had different instructors. In addition, the 11-item student perception measure that we developed contained questions that were nearly all positively worded. It is possible that the positive bias of these questions influenced participants' responses (Nisbett \& Wilson, 1977). Lastly, the content of the course was not identical between sections. The non-identical course content limitation is particularly problematic for the student performance analyses, and we acknowledge that those results should be interpreted with caution. We attempted to mitigate many of these limitations (e.g., controlling for differences in perceptions of instructor 
competence and approachability/warmth; averaging the three exam scores before assessing student performance), yet many factors were outside our control. For example, readers might note that the clicker sections were significantly smaller than the discussion section. Although we acknowledge that this is a major limitation in our design, class size was outside our control, as the registrar controlled course sizes. These inherent methodological problems limit the conclusions in this quasi-experimental study and preclude causal inferences from being made. Nevertheless, considering that such limitations are a common feature of research in real classrooms (Spangler \& Kiel, 2015), we believe the current research still provides insight into how clickers influence student perceptions and performance relative to a more labour-intensive active learning technique.

Future research should continue to examine the techniques instructors can integrate with clickers in order to maximise student engagement and performance. For instance, recent work has revealed that clickers can be combined with established study techniques to effectively increase student perceptions and performance (relative to other review methods; Lloyd et al., in press). In addition, researchers have noted that clickers have the potential to turn a lecture-based course into a course that integrates group discussions if students are given the opportunity to discuss each clicker question with neighbors (Blasco-Arcas et al., 2013; Daniel \& Tivener, 2016; Lantz, 2010). Other research has revealed that by combining clickers and student discussions instructors can maximise student understanding of the material (Daniel, \& Tivener, 2016; Smith et al., 2009). Therefore, future work should examine other ways in which clickers can be integrated with other active learning pedagogies, such as the discussion section pedagogy used in this study.

Future work should also examine if course level influences how these pedagogies are perceived or if course level influences the relationship between pedagogy type and performance. The current research implemented these pedagogies in an introduction course, and it may be the case that structured discussion groups lead to more favourable student outcomes (relative to clickers) in upper-level courses (Kalyuga, Ayres, Chandler, \& Sweller, 2003). Additionally, future work should consider how the amount of time spent participating in one of these pedagogies influences student perceptions and performance. Structured discussion groups take up significantly more time than clickers, which should enable students to process material in a more in-depth manner (Prince, 2004). Interestingly, however, results from the current research suggest that student performance was not higher in discussion sections than in clicker sections. Recent research has indicated that students learn just as well by answering quick comprehension questions relative to generating their own questions, which takes substantially more time (Lloyd et al., in press; see also Weinstein, McDermott, \& Roediger, 2010). This may be one explanation as to why performance did not differ between pedagogies. Thus, future work should more directly examine how time spent participating in clicker questions influences student perceptions and performance. Finally, this research specifically examined structured, student-led discussion groups. There are many other ways to implement discussion, such as think-pair-share methods, impromptu small-group discussions during a primarily lecture-focused class, whole-class discussions and the jigsaw classroom, which will differ in their benefits and drawbacks from those of the current discussion technique and of clickers. Additionally, there are other popular and widely adopted active learning techniques beyond clickers and discussion, such as in-class journalling or minute papers. Future research should also examine variation in these and other active learning techniques as well.

\section{Conclusion}

In sum, the current study used a mixed methods design and revealed that, in introduction courses, the clicker pedagogy was evaluated more favourably than structured, student-led discussion groups. Additionally, secondary analyses suggested that clickers had an equivalent or slightly more positive impact on performance compared to discussion groups. Although much of the past research on clickers has compared this technique to control methods, the current research offers some novel insight into how clickers compare to other effective active learning pedagogies. Specifically, by revealing that clickers have a unique effect on student evaluations, these results suggest that instructors of introduction courses should consider integrating clickers in some form in the classroom, particularly if instructors want a time-efficient way to improve student attitudes towards the chosen pedagogy. 


\section{References}

Anthis, K. (2011). Is it the clicker, or is it the question? Untangling the effects of student response system use. Teaching of Psychology, 38, 189-193. doi:10.1177/0098628311411895

Armbruster, P., Patel, M., Johnson, E., \& Weiss, M. (2009). Active learning and student-centered pedagogy improve student attitudes and performance in introductory biology. CBE-Life Sciences Education, 8, 203213. doi:10.1187/cbe.09-03-0025

Barkley, E. F., Cross, K. P., \& Major, C. H. (2014). Collaborative learning techniques: A handbook for college faculty. San Francisco, CA: John Wiley \& Sons.

Barnett, J. (2006). Implementation of personal response units in very large lecture classes: Student perceptions. Australasian Journal of Educational Technology, 22(4), 474-494. doi:10.14742/ajet.1281d

Benson, J. D., Szucs, K. A., \& Taylor, M. (2016). Student response systems and learning: Perceptions of the student. Occupational Therapy in Health Care, 30, 406-414. doi:10.1080/07380577.2016.1222644

Blasco-Arcas, L., Buil, I., Hernández-Ortega, B., \& Sese, F. J. (2013). Using clickers in class: The role of interactivity, active collaborative learning and engagement in learning performance. Computers \& Education, 62, 102-110. doi:10.1016/j.compedu.2012.10.019

Brady, M., Seli, H., \& Rosenthal, J. (2013). “Clickers” and metacognition: A quasi-experimental comparative study about metacognitive self-regulation and use of electronic feedback devices. Computers \& Education, 65, 56-63. doi:10.1016/j.compedu.2013.02.001

Braun, V., \& Clarke, V. (2006). Using thematic analysis in psychology. Qualitative Research in Psychology, 3, 77-101. doi:10.1191/1478088706qp063oa

Buskist, W., \& Benassi, V. A. (2012). Effective college and university teaching: Strategies and tactics for the new professoriate. Los Angeles, CA: Sage.

Chien, Y. T., Chang, Y. H., \& Chang, C. Y. (2016). Do we click in the right way? A meta-analytic review of clicker-integrated instruction. Educational Research Review, 17, 1-18. doi:10.1016/j.edurev.2015.10.003

Daniel, T., \& Tivener, K. (2016). Effects of sharing clickers in an active learning environment. Educational Technology \& Society, 19, 260-269. Retrieved from http://www.jstor.org/stable/jeductechsoci.19.3.260

Freeman, M., Blayney, P., \& Ginns, P. (2006). Anonymity and in class learning: The case for electronic response systems. Australasian Journal of Educational Technology, 22(4), 568-580. doi:10.14742/ajet.1286

Garrison, D. R., Anderson, T., \& Archer, W. (2001). Critical thinking, cognitive presence, and computer conferencing in distance education. American Journal of Distance Education, 15, 7-23. doi:10.1080/08923640109527071

Hake, R. R. (1998). Interactive-engagement versus traditional methods: A six-thousand-student survey of mechanics test data for introductory physics courses. American Journal of Physics, 66, 64-74. doi:10.1119/1.18809

Handelsman, J., Ebert-May, D., Beichner, R., Bruns, P., Chang, A., DeHaan, R., ... Wood, W. B. (2004). Scientific teaching. Science, 304, 521-522. doi:10.1126/science.1096022

Hunsu, N. J., Adesope, O., \& Bayly, D. J. (2016). A meta-analysis of the effects of audience response systems (clicker-based technologies) on cognition and affect. Computers \& Education, 94, 102-119. doi:10.1016/j.compedu.2015.11.013

Johnson, D. W., Johnson, R. T., \& Smith, K. A. (1998). Active learning: Cooperation in the college classroom (2nd ed.). Edina, MN: Interaction Book Co.

Kalyuga, S., Ayres, P., Chandler, P., \& Sweller, J. (2003). The expertise reversal effect. Educational Psychologist, 38, 23-31. doi:10.1207/S15326985EP3801_4

Kay, R. H., \& LeSage, A. (2009). Examining the benefits and challenges of using audience response systems: A review of the literature. Computers \& Education, 53, 819-827. doi:10.1016/j.compedu.2009.05.001

Kirschner, F., Paas, F., \& Kirschner, P. A. (2009). Individual and group-based learning from complex cognitive tasks: Effects on retention and transfer efficiency. Computers in Human Behavior, 25, 306-314. doi:10.1016/j.chb.2008.12.008

Kornell, N., Rabelo, V. C., \& Klein, P. J. (2012). Tests enhance learning: Compared to what? Journal of Applied Research in Memory and Cognition, 1, 257-259. doi:10.1016/j.jarmac.2012.10.002 
Lantz, M. E. (2010). The use of 'clickers' in the classroom: Teaching innovation or merely an amusing novelty? Computers in Human Behavior, 26, 556-561. doi:10.1016/j.chb.2010.02.014

Lloyd, E. P., Walker, R. J., Metz, M. A., \& Diekman, A. B. (in press). Comparing review strategies in the classroom: Self-testing yields more favorable student outcomes relative to question generation. Teaching of Psychology.

Martyn, M. (2007, January 1). Clickers in the classroom: An active learning approach. Educause Quarterly, 30, 71-74. Retrieved from http://er.educause.edu/articles/2007/1/clickers-in-the-classroom-anactive-learning-approach

Morgan, R. K. (2008). Exploring the pedagogical effectiveness of clickers. Insight: A Journal of Scholarly Teaching, 3, 31-36. Retrieved from ERIC database. (EJ888407)

Morling, B., McAuliffe, M., Cohen, L., \& DiLorenzo, T. M. (2008). Efficacy of personal response systems (“clickers”) in large, introductory psychology classes. Teaching of Psychology, 35, 45-50. doi:10.1080/00986280701818516

Nisbett, R. E., \& Wilson, T. D. (1977). The halo effect: Evidence for unconscious alteration of judgments. Journal of Personality and Social Psychology, 35, 250-256. doi:10.1037/0022-3514.35.4.250

Patry, M. (2009). Clickers in large classes: From student perceptions towards an understanding of best practices. International Journal for the Scholarship of Teaching and Learning, 3, 1-11. doi:10.20429/ijsotl.2009.030217

Poirier, C. R., \& Feldman, R. S. (2007). Promoting active learning using individual response technology in large introductory psychology classes. Teaching of Psychology, 34, 194-196. doi:10.1080/00986280701498665

Pratton, J., \& Hales, L. W. (1986). The effects of active participation on student learning. The Journal of Educational Research, 79, 210-215. doi:10.1080/00220671.1986.10885679

Prince, M. (2004). Does active learning work? A review of the research. Journal of Engineering Education, 93, 223-232. doi:10.1002/j.2168-9830.2004.tb00809.x

Shaffer, D. M., \& Collura, M. J. (2009). Evaluating the effectiveness of a personal response system in the classroom. Teaching of Psychology, 36, 273-277. doi:10.1080/00986280903175749

Smith, M. K., Wood, W. B., Adams, W. K., Wieman, C., Knight, J. K., Guild, N., \& Su, T. T. (2009). Why peer discussion improves student performance on in-class concept questions. Science, 323, 122-124. doi:10.1126/science.1165919

Spangler, B. R., \& Kiel, E. J. (2015). Topical versus chronological organization of lifespan development: Does it make a difference in student retention and understanding? Teaching of Psychology, 42, 73-78. doi:10.1177/0098628314562682

Springer, L., Stanne, M. E., \& Donovan, S. S. (1999). Effects of small-group learning on undergraduates in science, mathematics, engineering, and technology: A meta-analysis. Review of Educational Research, 69, 21-51. doi:10.3102/00346543069001021

Stenlund, T., Jönsson, F. U., \& Jonsson, B. (2016). Group discussions and test-enhanced learning: Individual learning outcomes and personality characteristics. Educational Psychology, 37, 145-156. doi:10.1080/01443410.2016.1143087

Stevens, D. P., \& Fontenot, G. (2017). Measuring clicker impact on student perceptions of course and instructor. International Journal of Innovation and Learning, 21, 21-34. doi:10.1504/IJIL.2017.080751

Stowell, J. R., \& Nelson, J. M. (2007). Benefits of electronic audience response systems on student participation, learning, and emotion. Teaching of Psychology, 34, 253-258. doi:10.1080/00986280701700391

Stowell, J. R., Oldham, T., \& Bennett, D. (2010). Using student response systems (“clickers”) to combat conformity and shyness. Teaching of Psychology, 37, 135-140. doi:10.1080/00986281003626631

Symister, P., VanOra, J., Griffin, K. W., \& Troy, D. (2014). Clicking in the community college classroom: Assessing the effectiveness of clickers on student learning in a general psychology course. The Community College Enterprise, 20, 10-24. Retrieved from ERIC database. (EJ1079630)

Trees, A. R., \& Jackson, M. H. (2007). The learning environment in clicker classrooms: Student processes of learning and involvement in large university-level courses using student response systems. Learning, Media and Technology, 32, 21-40. doi:10.1080/17439880601141179 
Weinstein, Y., McDermott, K. B., \& Roediger, H. L. (2010). A comparison of study strategies for passages: Rereading, answering questions, and generating questions. Journal of Experimental Psychology: Applied, 16, 308-316. doi:10.1037/a0020992

Wesp, R., \& Miele, J. (2008). Student opinions of the quality of teaching activities poorly predict pedagogical effectiveness. Teaching of Psychology, 35, 360-362. doi:10.1080/00986280802374617

Whitehurst, G. J. (2010). Education research: Past, present, future. In Policy perspectives. San Francisco, CA: WestEd. Retrieved from https://www.wested.org/online_pubs/pp-10-01.pdf

Yoder, J. D., \& Hochevar, C. M. (2005). Encouraging active learning can improve students' performance on examinations. Teaching of Psychology, 32, 91-95. doi:10.1207/s15328023top3202_2

Corresponding author: Ryan J. Walker, walkerrj@miamioh.edu

Australasian Journal of Educational Technology (c) 2018.

Please cite as: Walker, R. J., Spangler, B. R., Lloyd, E. P., Walker, B. L., Wessels, P. M., \& Summerville, A. (2018). Comparing active learning techniques: The effect of clickers and discussion groups on student perceptions and performance. Australasian Journal of Educational Technology, 34(3), 74-87.

https://doi.org/10.14742/ajet.3337 